\title{
Portion or Totality
}

National Cancer Institute

\section{Source}

National Cancer Institute. Portion or Totality. NCI Thesaurus. Code C103166.

An anatomical qualifier that describes the arrangement or apportioning of an entity within a body part, region or organ. 